\title{
Bisphenols, Benzophenones, and Bisphenol A Diglycidyl Ethers in Textiles and Infant Clothing
}

\author{
Jingchuan Xue, ${ }^{\dagger}$ Wenbin Liu, ${ }^{\dagger}$ and Kurunthachalam Kannan ${ }^{*}, \S_{\odot}$ \\ ${ }^{\dagger}$ Wadsworth Center, New York State Department of Health, and Department of Environmental Health Sciences, School of Public \\ Health, State University of New York at Albany, Empire State Plaza, P.O. Box 509, Albany, New York 12201-0509, United States \\ ${ }^{\ddagger}$ Research Center for Eco-Environmental Sciences, Chinese Academy of Sciences, 18 Shuangqing Road, Haidian District, Beijing \\ 100085, China
}

${ }^{\S}$ Biochemistry Department, Faculty of Science and Experimental Biochemistry Unit, King Fahd Medical Research Center, King Abdulaziz University, Jeddah, Saudi Arabia

\section{Supporting Information}

\begin{abstract}
Little is known with regard to the occurrence of potentially toxic chemicals in textiles and clothes. In this study, 77 textiles and infant clothing pieces were analyzed for the determination of bisphenols including bisphenol A (BPA) and bisphenol S (BPS), benzophenones, bisphenol A diglycidyl ethers (BADGEs), and novolac glycidyl ethers (NOGEs). BPA and BPS occurred in $82 \%$ and $53 \%$ of the textile samples, respectively, and at mean concentrations of 366 and $15 \mathrm{ng} / \mathrm{g}$, respectively. Benzophenone-3 (BP3) occurred in $70 \%$ of the samples at a mean concentration of $11.3 \mathrm{ng} / \mathrm{g}$. Among 11 BADGEs and NOGEs analyzed, BFDGE was the predominant compound, with a mean concentration of $13.6 \mathrm{ng} / \mathrm{g}$. Concentrations of target chemicals were assessed by fabric type, color, and uses. Socks contained the highest concentrations of BPA (mean: 1810 $\mathrm{ng} / \mathrm{g}$ ) with concentrations as high as $13300 \mathrm{ng} / \mathrm{g}$ in a $97 \%$ polyester fabric marketed for infants. Calculated dermal exposure dose to BPA by infants via textiles was as high as $7280 \mathrm{pg} / \mathrm{kg} \mathrm{BW} / \mathrm{d}$. This is the first study to report the occurrence of, and exposure to, BPA, BPS, BADGEs, and NOGEs in textiles and clothing.
\end{abstract}

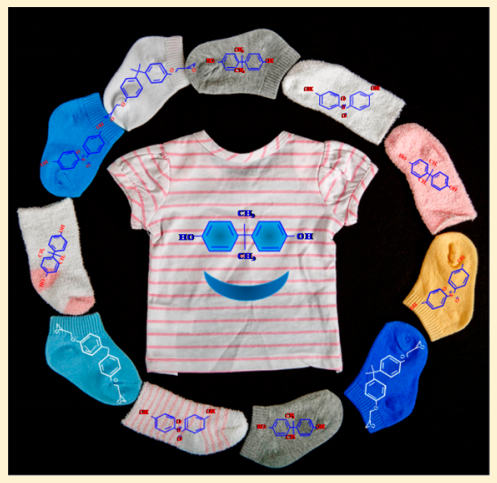

\section{INTRODUCTION}

Many chemicals used in consumer product-related applications are gaining widespread attention as contaminants of emerging concern. Bisphenols and their derivatives, as well as benzophenones, are among the chemicals falling into this category.

Bisphenol analogs (hereafter "bisphenols") are a group of chemicals that share the basic structure of two phenol groups, with hydroxy moieties at the para positions, and joined by a carbon or sulfur bridge. 2,2-Bis(4-hydroxyphenyl)propane, commonly known as bisphenol A (BPA), is the major compound of this chemical class. Other common bisphenols include bisphenol F (BPF) and bisphenol S (BPS). BPA can turn into bisphenol A diglycidyl ether (BADGE) by reaction with epichlorohydrin. ${ }^{1}$ Similarly, BPF can react with epicholorohydrin to form bisphenol $\mathrm{F}$ diglycidyl ether (BFDGE), which is also called two-ring ( $R$ )-novolac glycidyl ether (NOGE). NOGE is structurally similar to BADGE but contains more than two aromatic rings and glycidyl groups. ${ }^{2}$ The epoxy groups of BADGE and NOGE are highly reactive and can form derivatives with a variety of nucleophilic compounds. ${ }^{1,3}$ Common derivatives of these chemicals are the reaction products with water and hydrochloric acid, including BADGE. $\mathrm{H}_{2} \mathrm{O}$, BADGE $2 \mathrm{H}_{2} \mathrm{O}$, BADGE $\cdot \mathrm{HCl} \cdot \mathrm{H}_{2} \mathrm{O}, \mathrm{BADGE} \cdot \mathrm{HCl}$, BADGE $2 \mathrm{HCl}, \mathrm{BFDGE} \cdot 2 \mathrm{H}_{2} \mathrm{O}$, and BFDGE $2 \mathrm{HCl}$. In this report, BADGEs/NOGEs collectively refer to BADGE,
NOGE, and their derivatives. We also report on 2-hydroxy-4methoxybenzophenone, also known as oxybenzone or benzophenone-3 (BP3), which is a conjugated molecule that can absorb light.

Bisphenols, benzophenones, BADGEs, and NOGEs have been reported to be toxic in many laboratory animal studies and in vitro assays. ${ }^{4-14}$ Bisphenols have been shown to be estrogenic. ${ }^{4,5}$ BPA in particular has been associated with a variety of human health effects, including obesity, diabetes, breast and prostate cancer, and neurological and reproductive problems. ${ }^{15,16}$ Benzophenones have also been reported to elicit estrogenic and anti-androgenic effects. ${ }^{6,7}$ Apart from their endocrine-disrupting potentials, BADGEs/NOGEs have been linked to adverse reproductive and developmental effects. ${ }^{13,17}$ Although the carcinogenic effects of BADGEs/NOGEs are still unknown, a variety of in vitro bioassays have confirmed their genotoxic potentials. ${ }^{11,12,14}$

Bisphenols, benzophenones, and BADGEs/NOGEs are categorized as "high production volume (HPV) chemicals" by the U.S. Environmental Protection Agency (EPA; https:// iaspub.epa.gov/sor_internet/registry/substreg/list/details.

Received: February 7, 2017

Revised: $\quad$ March 31, 2017

Accepted: April 3, 2017

Published: April 3, 2017 
do?listId=74). BPA is typically used in the production of epoxy resins and polycarbonate plastics and is frequently found in consumer products such as thermal receipt papers, currency bills, personal care products, foodstuffs, and polycarbonate plastic bottles. ${ }^{18-21}$ Benzophenones are widely used as UV-light absorbers in sunscreens and photostabilizers in synthetic resins. $^{22}$ BADGEs/NOGEs are used as building blocks in the production of epoxy resins, which are widely used in coatings and adhesives. ${ }^{1}$ BADGE/NOGE and their derivatives have been reported to occur in canned foods. ${ }^{23,24}$ In general, bisphenols, benzophenones, and BADGEs/NOGEs are also widespread environmental contaminants found in indoor air, dust, sludge, and in human specimens such as urine, plasma, and adipose tissue. ${ }^{25-32}$

The textile industry has grown rapidly in recent years, especially in developing countries, and this growth is expected to continue. A wide range of chemicals are used in textile industry in the production of fibers, yarns, and final fabrics. A survey conducted by the Transparency Market Research firm in 2015 indicated that like the textile market itself, the textile chemical market is anticipated to grow at $3.7 \%$ annually from its current U.S. market value of $\$ 21$ billion globally. Final fabrics produced by the industry are estimated to contain around $27 \%$ chemicals (by weight) if made of $100 \%$ natural fibers, with significantly greater chemical amounts used in synthetic fibers. $^{33}$

Chemicals used in fabric production can be categorized as textile auxiliaries, textile chemicals, and finishes. ${ }^{34}$ Textile auxiliaries refer to those substances that are used in purifying natural fibers. ${ }^{34}$ Textile chemicals are the basic chemicals used in the production of fabric, which include dyes and UV-light absorbers. ${ }^{34}$ Textile finishes are applied to improve the natural properties of the fabric and to increase its lifespan. ${ }^{34}$ A variety of additives are employed in this process, such as antioxidants for the prevention of oxidation and degradation of finishes. ${ }^{35}$ BPA is used as an intermediate chemical in the manufacture of antioxidants and dyes. ${ }^{35}$ BPA derivatives are also employed in textile processing. For example, usage of $5 \%$ polyethylene glycol bisphenol A ether diacrylate has been reported as the finish in the production of polyester fabrics. ${ }^{34}$ Plastisol PVC print, which is used in the production of synthetic leather, is also a suspect source of BPA in textile production. ${ }^{36}$ Benzophenone is used in textiles to prevent oxidative damage from sunlight. BADGE/ NOGE-based epoxy resins are extensively used as coatings and adhesives, and thus they may also be used in the production of textiles.

Although their use is clearly widespread, measured occurrence of these potentially toxic substances in textiles has never been investigated before. Due to their high level of use in daily life, textiles such as clothing and bedding can be a significant potential source of dermal human exposure to toxic chemicals. Infants wearing cloth diapers may be at risk for additional exposure due to nearly constant wear. To address these questions in this study, several types of textiles, including infant clothing and diapers, were collected from local stores in Albany, New York, USA, to investigate the occurrence of bisphenols, benzophenones, BADGEs, and NOGEs. In addition, we assessed dermal exposure to these substances by infants.

\section{MATERIALS AND METHODS}

Standards and Reagents. Information regarding standards and reagents used in this study is provided in the Supporting Information.

Sample Collection and Preparation. In April 2016, we collected 77 textile samples from local stores in Albany, New York, USA. The samples encompassed raw textiles, cloth diapers, blankets, and clothing marketed for infants aged below 1 year. The textile samples collected represented various fabric types (e.g., cotton, polyester, nylon), colors, and countries of origin. Several printed portions within garments were analyzed for specific tailored garments containing graphics/prints. Eighteen (100\% cotton) raw textiles from China and one $70 \%$ polyester (30\% rayon) raw textile from India, with a range of different colors, were also analyzed. Fourteen socks for newborns containing $97-98 \%$ polyester, $1-2 \%$ Spandex, and up to $1 \%$ latex rubber were analyzed (all originated from China). Additionally, we analyzed three 94\% nylon/6\% Spandex blend newborn-size tights originating from Ecuador, as well as thirty-five $100 \%$ cotton or cotton/polyester blend bodysuits, pants, trousers, skirts, and shirts originating from China $(n=9)$, India $(n=10)$, Bangladesh $(n=2)$, Sri Lanka $(n$ $=2)$, Cambodia $(n=8)$, Vietnam $(n=2)$, and Salvador $(n=2)$. Four pre-folded cloth diapers (100\% cotton) and two infant blankets ( $100 \%$ polyester; all made in China) were also analyzed. A detailed list of samples analyzed in this study is provided in the Supporting Information (Table S1). The textile samples were stored in polyethylene bags in the dark until analysis.

The analytical method has been described in detail elsewhere. ${ }^{37}$ Briefly, $1.4 \mathrm{~g}$ pieces of each textile were cut and placed in $15 \mathrm{~mL}$ polypropylene (PP) tubes, and $50 \mathrm{ng}$ of isotope-labeled internal standards mixture $\left({ }^{13} \mathrm{C}_{12}-\mathrm{BP} 3,{ }^{13} \mathrm{C}_{12}\right.$ $\mathrm{BPA}$, and $d_{6}$-BADGE) was spiked. Ten milliliters of a mixture of acetone and dichloromethane $(\mathrm{v} / \mathrm{v} 1 / 4)$ was used for extraction. After ultrasonication for $20 \mathrm{~min}$ and centrifugation at $5000 \mathrm{~g}$ for $5 \mathrm{~min}$, the solvent layer was transferred to another $15 \mathrm{~mL}$ PP tube. The samples were extracted twice, and the supernatants were combined. After evaporation to near dryness under a gentle stream of nitrogen, $1 \mathrm{~mL}$ of methanol was added and filtered through a $0.2 \mu \mathrm{m}$ nylon filter prior for instrumental analysis.

For the analysis of bisphenols and benzophenones, we carried out chromatographic separation using a Shimadzu Prominence Modular HPLC system (Shimadzu Corporation, Kyoto, Japan) connected with a Betasil C18 column (2.1 mm $\times$ $100 \mathrm{~mm}, 5 \mu \mathrm{m}$ ) (Thermo Electron Corporation, Waltham, MA, USA). Identification and quantification of target analytes were performed with an Applied Biosystems API 3200 electrospray triple quadrupole-mass spectrometer (ESI-MS/MS) (Applied Biosystems, Foster City, CA, USA). The details of instrumental analysis and compound specific analytical parameters are shown in the Supporting Information.

For the analysis of BADGE, BFDGE, 3R-NOGE, 4R-NOGE, and their derivatives, the chromatographic separation was carried out using an Agilent 1100 Series HPLC system (Agilent Technologies Inc., Santa Clara, CA, USA). Identification and quantification of target analytes were performed with an Applied Biosystems API 2000 ESI-MS/MS. The details of instrumental analysis and compound specific parameters are shown in the Supporting Information. 
Quality Assurance and Quality Control. Bisphenols, benzophenones, BADGEs, and NOGEs were quantified by an internal standard method, with responses relative to ${ }^{13} \mathrm{C}_{12}$-BPA, ${ }^{13} \mathrm{C}_{12}-\mathrm{BP} 3$, and $d_{6}$-BADGE, respectively. $\mathrm{A} 9$ - to 11-point standard calibration curve, with concentrations ranging from 0.1 to $200 \mathrm{ng} / \mathrm{mL}$, was used in the quantification of the target analytes. The regression coefficients $(r)$ were $\geq 0.99$ for all calibration curves. The limits of quantification (LOQs) were determined on the basis of the lowest point of the calibration standard with a signal-to-noise $(\mathrm{S} / \mathrm{N})$ ratio of $>10$. Method LOQs (MLOQs) were estimated as 10 times the $\mathrm{S} / \mathrm{N}$ ratio based on the matrix-spiked samples. As a check for instrumental drift in response factors, we injected a midpoint calibration standard after every 10 samples. A pure solvent (methanol) was injected after every 10 samples to monitor for carryover of target analytes. We analyzed several procedural blanks with each batch of samples to determine the contamination arising from laboratory materials and solvents. Throughout the analysis, three different types of textiles were selected for preand post-extraction matrix spike (MS) by spiking known amounts of target analytes and passing them through the entire analytical procedure.

Method Performance. The MLOQs of the target compounds in textiles ranged from 0.1 to $5 \mathrm{ng} / \mathrm{mL}(0.74$ to $14.7 \mathrm{ng} \cdot \mathrm{g}^{-1}$ ) (Table S2 and S3). The average sample weight was used for MLOQ calculation. Trace concentrations of BADGE. $2 \mathrm{H}_{2} \mathrm{O}(2.43 \mathrm{ng} / \mathrm{mL})$ were found in several procedural blanks, and these concentrations were subtracted from the concentrations measured in samples (Table S2). Select chromatograms showing procedural blank, lowest calibration standard at the MLOQ, and samples with low concentrations for BADGE. $2 \mathrm{H}_{2} \mathrm{O}$ are shown in Figure $\mathrm{S} 1$. Relative recoveries were computed based on the ratio of the signal for the analyte to that of the internal standard. Relative recoveries of benzophenones and bisphenols in textiles ranged from $74 \%$ to $124 \%$ and from $60 \%$ to $140 \%$, respectively. Relative recoveries of BADGEs and NOGEs ranged from $55 \%$ to $120 \%$. The recoveries varied depending on the chemical and matrix (textile material) (Table S3). BPA, BPS, and BP3, which were predominant in textiles, showed excellent recoveries in all the three matrices analyzed (Table S3). Relative standard deviations (RSDs) for all the target analytes were below 30\% (Table S3).

Data Analysis. Statistical analyses were performed with statistics software package R v.3.1.0 and Microsoft Excel 2007. For the calculation of arithmetic mean (mean) and standard deviation (SD) of left-censored data, robust regression-onorder statistics (ROS) were used. ${ }^{38,39}$ Although the data were assumed to follow a log-normal distribution, ROS is resistant to non-normality, even for small sample sizes. A probability plot was used to test log-normal distribution of the data. To examine the relationship between chemicals, Spearman (when data did not follow a normal distribution after logarithmic transformation) or Pearson (when data followed a normal distribution after logarithmic transformation) correlation analysis was used. Only those samples with measurable concentrations of target analytes were used when performing correlation analyses. To assess the difference between means, a Student's $t$-test (when data followed a normal distribution after logarithmic transformation) or Mann-Whitney $U$ test (when data did not follow a normal distribution after logarithmic transformation) was used. A Shapiro-Wilk test and quantilequantile (Q-Q) plot were used to determine the normality of the data. Statistical significance was set at $p<0.05$.
Dermal exposure to the target chemicals present in textiles by infants was calculated using the eq 1 :

$$
\mathrm{EXP}_{\text {derm }}=\frac{C \times D \times \mathrm{SA} \times F_{\text {mig }} \times F_{\text {contact }} \times F_{\text {pen }} \times T \times N}{B W}
$$

where $\operatorname{EXP}_{\text {derm }}$ is the dermal absorption dose (pg/kg BW/d), C is the concentration of the chemicals in textiles (ng/g), $D$ is the density of the textile $\left(\mathrm{mg} / \mathrm{cm}^{2}\right)$, SA is the skin contact surface area, ${ }^{40} F_{\text {mig }}$ is the migration rate of chemicals to the skin per day $(0.0051 / \mathrm{d}),{ }^{41} F_{\text {contact }}$ is the fraction of contact area for skin $(1$, unitless), ${ }^{41} F_{\text {pen }}$ is the penetration rate of chemicals into body (0.01, unitless), ${ }^{41} T$ is the contact duration between textiles and skin (assumed to be $1 \mathrm{~d}$ ), ${ }^{42} \mathrm{~N}$ is the mean number of events per day (assumed to be $11 / \mathrm{d}$ ), ${ }^{42}$ and BW is the average body weight for infants. ${ }^{40}$

\section{RESULTS AND DISCUSSION}

Bisphenols, Benzophenones, BADGEs, and NOGEs in Textiles. Among the target chemicals analyzed in this study, bisphenols presented higher detection rates (DR) and concentrations in textiles than benzophenones, BADGEs, and NOGEs (Table 1). BPA was measured at a detection rate (DR)

Table 1. Overall Concentrations (ng/g) of Bisphenols, Benzophenones, Bisphenol A Diglycidyl Ether (BADGE), and Their Derivatives in Textiles $(n=77)$ Collected from Albany, New York, USA ${ }^{a}$

\begin{tabular}{|c|c|c|c|c|c|}
\hline$n=77$ & $\begin{array}{l}\mathrm{DR} \\
(\%)\end{array}$ & mean & SD & median & range \\
\hline BPA & 82 & 366 & 1690 & 10.7 & $<2.21-13300$ \\
\hline BPS & 53 & 15.0 & 58.9 & 1.02 & $<0.74-394$ \\
\hline $\mathrm{BPF}$ & 5.2 & 6.70 & 25.3 & 0.32 & $<14.7-194$ \\
\hline BPP & 5.2 & 0.23 & 0.99 & 0.004 & $<0.74-7.96$ \\
\hline BP3 & 70 & 11.3 & 19.9 & 5.94 & $<2.21-157$ \\
\hline 4-OH-BP & 7.8 & 0.41 & 1.01 & 0.10 & $<1.47-7.66$ \\
\hline BP1 & 1.3 & n.a. & n.a. & n.a. & $<1.10-1.21$ \\
\hline $\begin{array}{c}\text { BADGE. } \\
2 \mathrm{H}_{2} \mathrm{O}\end{array}$ & 22 & 1.92 & 2.84 & 0.82 & $<1.47-13.1$ \\
\hline BADGE & 7.8 & 0.23 & 0.62 & 0.04 & $<0.74-4.37$ \\
\hline $\begin{array}{l}\text { BADGE } \cdot \mathrm{HCl} \cdot \\
\quad \mathrm{H}_{2} \mathrm{O}\end{array}$ & 16 & 7.32 & 11.9 & 2.88 & $<1.47-62.9$ \\
\hline BFDGE & 29 & 13.6 & 27.2 & 2.44 & $<1.47-132$ \\
\hline $\mathrm{BFDGE} \cdot 2 \mathrm{H}_{2} \mathrm{O}$ & 1.3 & n.a. & n.a. & n.a. & $<3.68-79.0$ \\
\hline 3R-NOGE & 25 & 13.3 & 30.4 & 1.47 & $<0.74-174$ \\
\hline 4R-NOGE & 12 & 1.77 & 3.54 & 0.64 & $<2.94-27.2$ \\
\hline
\end{tabular}

${ }^{a} \mathrm{DR}=$ detection rate; $\mathrm{SD}=$ standard deviation; n.a. = not available.

of $82 \%$ at concentrations that ranged from $<2.21$ to $13300 \mathrm{ng} /$ $\mathrm{g}($ mean $\pm \mathrm{SD}=366 \pm 1690 \mathrm{ng} / \mathrm{g})$ (Table 1$)$. The highest concentration of BPA, $13300 \mathrm{ng} / \mathrm{g}$, was found in a gray polyester (97\%) socks for 6-12 month old infants. Although BPA is not expected to be directly used in textile production, several intermediates used in textile production, including dyes, may be the source for this compound. ${ }^{35}$ For example, polyethylene glycol bisphenol A ether diacrylate is now used in the production of woven polyester fabrics. ${ }^{34}$

Among various types of fabrics analyzed, 14 socks analyzed in this study contained the highest concentrations of BPA (Table 2 ). These socks were all made of $97-98 \%$ polyester fabrics. In recent years, recycled plastic bottles made of polyethylene and polycarbonate have begun to be used for the production of polyester fibers woven into clothes, including socks. Thus, it 
Table 2. Concentrations (ng/g) of Bisphenols, Benzophenones, Bisphenol A Diglycidyl Ether (BADGE), and Their Derivatives in Textiles Sorted by Their Use ${ }^{a}$

\begin{tabular}{|c|c|c|c|c|c|}
\hline & $\begin{array}{l}\mathrm{DR} \\
(\%)\end{array}$ & mean & SD & median & Range \\
\hline \multicolumn{6}{|c|}{ Raw Textiles $(n=19)$} \\
\hline BPA & 32 & 105 & 418 & 0.02 & $<2.21-1830$ \\
\hline BPS & 37 & 6.19 & 15.9 & 0.29 & $<0.74-67.5$ \\
\hline BP3 & 37 & 13.4 & 36.2 & 0.59 & $<2.21-157$ \\
\hline BP1 & 5.3 & n.a. & n.a. & n.a. & 1.21 \\
\hline $\begin{array}{c}\text { BADGE. } \\
2 \mathrm{H}_{2} \mathrm{O}\end{array}$ & 32 & 2.32 & 3.50 & 0.77 & $<1.47-12.0$ \\
\hline $\begin{array}{l}\text { BADGE. } \\
\mathrm{HCl} \cdot \mathrm{H}_{2} \mathrm{O}\end{array}$ & 63 & 21.1 & 17.6 & 15.8 & $<1.47-62.9$ \\
\hline BFDGE & 68 & 43.8 & 38.4 & 31.3 & $<1.47-132$ \\
\hline 3R-NOGE & 63 & 40.9 & 34.0 & 28.8 & $<0.74-126$ \\
\hline \multicolumn{6}{|c|}{ Cloth Diaper/Blanket $(n=6)$} \\
\hline BPA & 100 & 37.3 & 27.2 & 38.7 & $6.29-73.1$ \\
\hline BPS & 17 & n.a. & n.a. & n.a. & 1.09 \\
\hline ВРP & 33 & n.a. & n.a. & n.a. & $1.10 ; 3.04$ \\
\hline BP3 & 17 & n.a. & n.a. & n.a. & 5.56 \\
\hline BFDGE & 17 & n.a. & n.a. & n.a. & 9.49 \\
\hline 3R-NOGE & 50 & 3.53 & 4.28 & 1.71 & $<0.74-11.1$ \\
\hline \multicolumn{6}{|c|}{ Clothes $(n=38)$} \\
\hline BPA & 98 & 15.5 & 18.7 & 9.92 & $<2.21-111$ \\
\hline BPS & 61 & 2.72 & 3.89 & 1.23 & $<0.74-16.7$ \\
\hline BPF & 11 & 12.9 & 35.1 & 1.32 & $<14.7-194$ \\
\hline BP3 & 92 & 12.4 & 12.0 & 9.18 & $<2.21-55.0$ \\
\hline 4-OH-BP & 7.9 & 0.72 & 0.61 & 0.53 & $<1.47-2.94$ \\
\hline $\begin{array}{l}\text { BADGE. } \\
2 \mathrm{H}_{2} \mathrm{O}\end{array}$ & 11 & 0.82 & 2.31 & 0.08 & $<1.47-13.1$ \\
\hline BADGE & 16 & 0.43 & 0.84 & 0.12 & $<0.74-4.37$ \\
\hline BFDGE & 16 & 3.67 & 13.5 & 0.15 & $<1.47-81.9$ \\
\hline $\begin{array}{c}\text { BFDGE. } \\
2 \mathrm{H}_{2} \mathrm{O}\end{array}$ & 2.6 & n.a. & n.a. & n.a. & 79.0 \\
\hline 3R-NOGE & 11 & 6.17 & 28.7 & 0.002 & $<0.74-174$ \\
\hline 4R-NOGE & 5.3 & n.a. & n.a. & n.a. & $3.94 ; 6.31$ \\
\hline \multicolumn{6}{|c|}{ Socks $(n=14)$} \\
\hline BPA & 100 & 1810 & 3700 & 396 & $186-13300$ \\
\hline BPS & 71 & 66.8 & 128 & 5.92 & $<0.74-394$ \\
\hline BP3 & 86 & 8.27 & 7.60 & 5.92 & $<2.21-31.7$ \\
\hline 4-OH-BP & 21 & 0.92 & 2.06 & 0.1 & $<1.47-7.66$ \\
\hline $\begin{array}{l}\text { BADGE. } \\
2 \mathrm{H}_{2} \mathrm{O}\end{array}$ & 50 & 3.62 & 3.28 & 2.15 & $<1.47-10.5$ \\
\hline BFDGE & 14 & n.a. & n.a. & n.a. & $14.5 ; 18.9$ \\
\hline 4R-NOGE & 50 & 5.97 & 6.68 & 4.32 & $<2.94-27.2$ \\
\hline
\end{tabular}

${ }^{a} \mathrm{DR}=$ detection rate; $\mathrm{SD}=$ standard deviation; n.a. $=$ not available.

seems likely that the source of BPA found in polyestercontaining socks is from the recycled plastic bottles used as raw materials in the production of polyester.

Due to growing public concerns about the use of BPA in consumer goods, use of BPS was introduced as a BPA-free alternative. However, studies show that BPS possesses genotoxicity and estrogenic activity similar to those of BPA. ${ }^{4}$ In the current study, BPS was the second most detected compound in our samples, with a DR of 53\%, and the concentrations ranged from $<0.74$ to $394 \mathrm{ng} / \mathrm{g}$, with a mean concentration of $15 \mathrm{ng} / \mathrm{g}$ (Table 1 ).

Of the four benzophenones measured, BP3 was the most abundant chemical, found at a mean concentration of $11.3 \mathrm{ng} / \mathrm{g}$
(DR, 70\%; range, <2.21-157) (Table 1 ). BP3 is commonly used as a sunscreen agent to block harmful UV rays. ${ }^{43} \mathrm{~A}$ significant positive correlation was found between the concentrations of BPA and BP3 $(r=0.28, \mathrm{p}=0.05)$ in textiles, when only those samples with measurable concentrations were examined (Figure 1a). This indicates the potential for co-exposure to the two substances from certain textiles.

Epoxy resins are commonly used in the process of finishing of textile products and as dye-fixers. ${ }^{44}$ Among the 11 BADGEs and NOGEs analyzed, BFDGE was found in $29 \%$ of the samples. This was the most frequently detected compound in this chemical class, followed by 3R-NOGE (DR, 25\%) and BADGE $2 \mathrm{H}_{2} \mathrm{O}$ (DR, 22\%). Mean concentrations of BFDGE, 3R-NOGE, and BADGE $2 \mathrm{H}_{2} \mathrm{O}$ in textiles were $13.6,13.3$, and $1.92 \mathrm{ng} / \mathrm{g}$, respectively (Table 1). Significant positive correlations were also observed between BFDGE, 3R-NOGE, and $\mathrm{BADGE} \cdot \mathrm{HCl} \cdot \mathrm{H}_{2} \mathrm{O}$ concentrations when only those samples with measurable values were used in the calculations (Figure $1 \mathrm{~b}-\mathrm{d}$ ). This suggests that BADGEs and NOGEs are potentially used together and/or may form derivatives during textile processing.

Contaminants in Relation to Types of Fabrics and Clothes. Textile products analyzed in this study were grouped into four categories, including (1) raw textiles, (2) blankets and cloth diapers, (3) clothes (bodysuits for infants, shirts, pants, and skirts), and (4) socks. BADGEs and NOGEs were found at higher DRs and concentrations in raw textiles than in blankets/ diapers, clothes, or socks (Figure 2a). BFDGE and 3R-NOGE were found in $63-68 \%$ of the raw textile samples, at concentrations ranging from $<1.47$ to $132 \mathrm{ng} / \mathrm{g}$ (mean $\pm \mathrm{SD}$, $43.8 \pm 38.4 \mathrm{ng} / \mathrm{g}$ ) and from $<0.74$ to $126 \mathrm{ng} / \mathrm{g}$ (mean $\pm \mathrm{SD}$, $40.9 \pm 34.0 \mathrm{ng} / \mathrm{g}$ ), respectively (Table 2 ). BADGE $\cdot \mathrm{HCl} \cdot \mathrm{H}_{2} \mathrm{O}$ was detected in $63 \%$ of raw textile samples (Table 2). In contrast, BPA and BPS concentrations in clothing and socks were approximately 3-5 times greater than those found in raw textiles, at 499 and $19.9 \mathrm{ng} / \mathrm{g}$, respectively (Table S6). Greater concentrations of BPA and BPS were found in socks (mean, 1810 and $66.8 \mathrm{ng} / \mathrm{g}$, respectively) than in clothes (15.5 and $2.72 \mathrm{ng} / \mathrm{g}$, respectively) (Table 2 ).

Concentrations of BPA, BPS, and BP3 in clothing $(n=52)$ were further examined based on the type of fabric, color, and uses. Mean \pm SD concentrations of BPA and BPS were $1110 \pm$ 2980 and $41 \pm 104 \mathrm{ng} / \mathrm{g}$, respectively, in clothing exclusively made of synthetic fibers (100\%, $98 \%$, and $97 \%$ polyester or $94 \%$ nylon) (Figure 2b; Table S7). The concentrations of BPA and BPS in clothing made primarily of synthetic fibers were approximately 72 and 13 times greater than those found in clothing exclusively made of $100 \%$ cotton or a $60 \%$ cotton blend (Figure 2b; Table S7). When the data were combined, the highest mean concentration of BPA was found in clothing that contains $97 \%$ polyester $(2300 \pm 4330 \mathrm{ng} / \mathrm{g})$, followed by $98 \%$ polyester $(600 \pm 484 \mathrm{ng} / \mathrm{g})$, while the lowest concentration was found in $100 \%$ cotton fabric $(8.64 \pm 7.90$ $\mathrm{ng} / \mathrm{g}$ ) (Table S7). However, much lower mean concentrations of BPA were found in clothing made of $100 \%$ polyester (15.3 \pm $10.5 \mathrm{ng} / \mathrm{g})$ and $94 \%$ nylon $(15.7 \pm 4.99 \mathrm{ng} / \mathrm{g})$ in comparison to the clothing made of $97 / 98 \%$ polyester (Table S7). A similar trend was observed for BPS (Table S7). In all the 97-98\% polyester sock samples analyzed, polyester was blended with other fabrics such as 1-2\% Spandex and 1\% latex rubber. Spandex is a synthetic fiber used in the clothing industry for its elasticity and strength. This fiber is mainly used in active wear, hosiery, elastic waistbands, socks, gloves, underwear, and many 

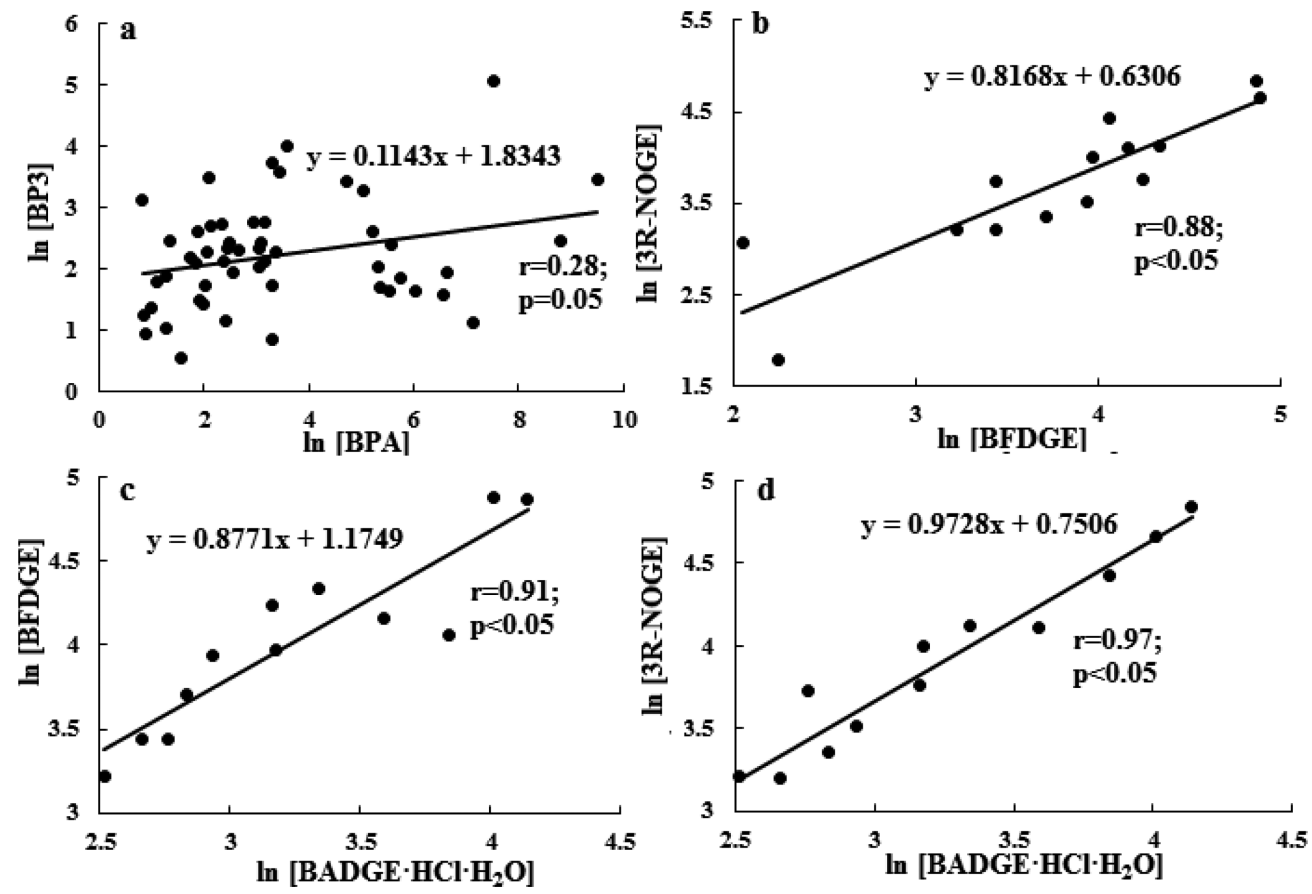

Figure 1. Correlation between $\ln$ concentrations of chemicals analyzed in textiles from Albany, New York, USA. (a) ln [BPA] vs ln [BP3]; (b) $\ln [\mathrm{BFDGE}]$ vs $\ln [3 \mathrm{R}-\mathrm{NOGE}] ;$ (c) $\ln [\mathrm{BFDGE}]$ vs $\ln \left[\mathrm{BADGE} \cdot \mathrm{HCl} \cdot \mathrm{H}_{2} \mathrm{O}\right]$; (d) $\ln [3 \mathrm{R}-\mathrm{NOGE}]$ vs $\ln \left[\mathrm{BADGE} \cdot \mathrm{HCl} \cdot \mathrm{H}_{2} \mathrm{O}\right]$. Note: only those samples with measurable levels of target chemicals are presented in this calculation.
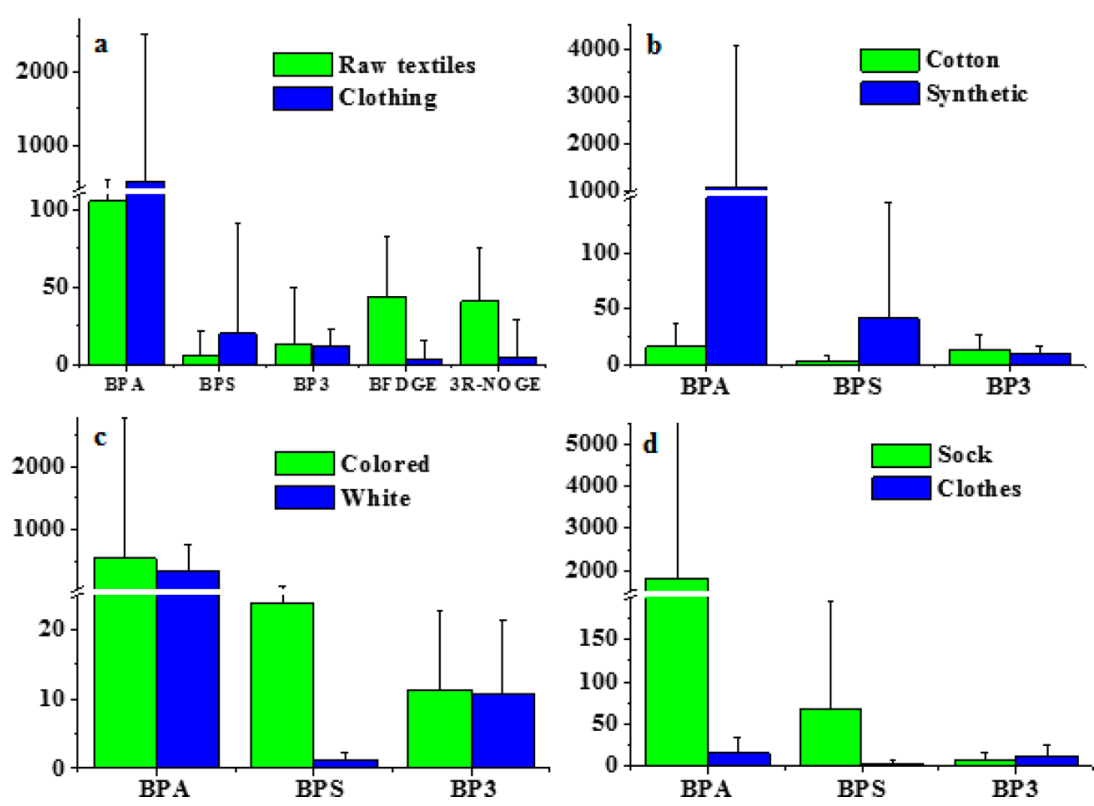

Figure 2. Concentrations (mean \pm SD) of bisphenol A (BPA), bisphenol S (BPS), benzophenone-3 (BP3), bisphenol F diglycidyl ether (BFDGE), and $3 R$-novolac glycidyl ether (NOGE) in different categories of textiles: (a) raw textiles vs clothing; (b) cotton vs synthetic fabric; (c) colored vs white; (d) socks vs bodysuits.

other skin-tight clothing types. An estimated $80 \%$ of clothing sold in the United States contained Spandex in 2010 (http:// www.npr.org/2011/12/11/143003539/spandex-has-stretchedwith-u-s-waistlines). It is probable that the high concentration of BPA found in $97-98 \%$ polyester fabric is related to its combination with Spandex. No significant difference was observed for BP3 concentrations between clothing made of cotton and synthetic fibers (Table S7). The relationships between color of textiles and concentrations of target chemicals are presented in Table S8. Higher mean concentrations of BPA and BPS were observed in colored clothing than in white textiles (Figure 2c; Table S8).

The clothing samples analyzed in this study were grouped into: newborn clothes, including bodysuits (sizes 0-3 months, 3-6 months, 6-9 months, and 12 months); socks for newborns; and socks for 6-12 months. Higher concentrations of BPA and BPS were found in socks than in bodysuits (Figure 2d; Table S9). The highest mean \pm SD concentration of BPA was found in socks for 6-12 month old infants at $2300 \pm 4330$ $\mathrm{ng} / \mathrm{g}$, followed by newborn socks $(600 \pm 484 \mathrm{ng} / \mathrm{g})$ (Table 
Table 3. Mean Dermal Exposure Dose (pg/kg BW/d) to Bisphenols, Benzophenones, Bisphenol A Diglycidyl Ether (BADGE), and Their Derivatives from Textiles for Newborn to 1-Year-Old Infants

\begin{tabular}{lccccccc}
\multicolumn{1}{c}{ age group } & BPA & BPS & $\sum[\mathrm{BPs}]$ & BP3 & $\sum[\mathrm{BzPs}]$ & BFDGE & 3R-NOGE \\
\hline newborns $(<1$ month) & 248 & 10.1 & 262 & 7.62 & 7.90 & 9.20 & 7.62 \\
1 to $<3$ months & 229 & 9.38 & 243 & 7.05 & 7.31 & 8.52 & 7.05 \\
3 to $<6$ months & 210 & 8.61 & 223 & 6.48 & 6.71 & 7.82 & 6.48 \\
6 to $<12$ months & 201 & 8.20 & 213 & 6.17 & 6.39 & 7.45 & 6.17 \\
\hline
\end{tabular}

S9). Among bodysuits, the highest mean \pm SD concentration of BPA $(28.3 \pm 30.4 \mathrm{ng} / \mathrm{g})$ was found in 3-6 month old infant clothes (Table S9). The highest BPS concentration was found in the socks for newborns at $101 \pm 196 \mathrm{ng} / \mathrm{g}$ (Table S9). Similarly, the highest mean concentration of BPS was found in newborn bodysuits at $4.37 \pm 4.79 \mathrm{ng} / \mathrm{g}$ (Table S9). No significant difference was found in the concentrations of BP3 between bodysuits and socks (Table S9). All of the sock samples analyzed in this study originated from China. After excluding socks, no significant differences were observed in the concentrations of BPA and BPS in textiles between countries of origin. It is worth noting that each newborn sock weighed between 4.7 and $5.7 \mathrm{~g}$ (mean, $5.2 \mathrm{~g}$ ). On the basis of the respective median and maximum BPA concentrations of 396 and $13300 \mathrm{ng} / \mathrm{g}$, the total amount of this compound present in each sock was estimated to be $2100 \mathrm{ng}$ and $69200 \mathrm{ng}$, respectively. This amount is not trivial and can be an important source of exposure in children.

Dermal Exposure Assessment for Infants. Following guidelines provided in the the U.S. EPA Exposure Factors Handbook, we calculated the dermal exposure dose to bisphenols, benzophenones, BADGEs, and NOGEs for infants at 0-1 months (newborns), 1-3 months, 3-6 months, and 612 months. ${ }^{40}$ The mean concentrations of the target chemicals measured in all textile samples were used for the exposure assessment. The skin surface covered by textiles was assumed to be the total body surface area of the infants for each age group (2040, 2310, 2660, and $3160 \mathrm{~cm}^{2}$, respectively). ${ }^{40}$ The body weights of infants for the above four categories were 4.8, 5.9, 7.4 , and $9.2 \mathrm{~kg}$, respectively. ${ }^{40}$ Average density $\left(22.4 \mathrm{mg} / \mathrm{cm}^{2}\right)$ was used in the conversion of weight of textile samples to area of textile samples.

The estimated body weight adjusted daily mean dermal exposure doses to BPA, BPS, BP3, BFDGE, and 3R-NOGE by newborns and infants up to 1 year are shown in Table 3. Dermal BPA exposure doses from textiles ranged from $201 \mathrm{pg} /$ $\mathrm{kg} \mathrm{BW} / \mathrm{d}$ for 6-12 months old infant to $248 \mathrm{pg} / \mathrm{kg} \mathrm{BW} / \mathrm{d}$ for newborns. BP3 exposure doses ranged from 6.17 to $7.62 \mathrm{pg} /$ $\mathrm{kg} \mathrm{BW/d}$. BPA exposure doses are similar to those reported for inhalation exposure by infants. ${ }^{30}$ Dermal BPA exposure doses from some textiles were as high as $7280 \mathrm{pg} / \mathrm{kg} \mathrm{BW} / \mathrm{d}$ for newborns. Among clothes, socks contributed most to BPA exposures in infants.

This study presents the first significant evidence that textiles are a source of exposure to BPA and similar chemicals, and that these chemicals are present at measurable levels in textile products, including those worn or utilized by newborns and infants. The study also provides estimates of the potentially high exposure doses to young children wearing or using these textile products. Occurrence of elevated concentrations of nonylphenol ethoxylate, phthalates, perfluorochemicals, and metals from textiles has been reported. ${ }^{45}$ Nevertheless, the study has several limitations. First, the sample size is small, and the textile samples were taken from a limited geographic area and a small number of stores. Also, all samples were new clothing and textiles and were analyzed prior to washing. It is likely that washing generally removes some of the contaminants present in textiles; therefore, further studies looking at concentrations in washed textiles are needed. The presence of toxic chemicals in clothing has implications for pollution in the aquatic environment, as these chemicals can leach during washing. Despite these limitations, our preliminary findings are provocative and highlight the need for further study of potential health risks from dermal exposure to chemicals present in textiles.

\section{ASSOCIATED CONTENT}

\section{S Supporting Information}

The Supporting Information is available free of charge on the ACS Publications website at DOI: 10.1021/acs.est.7b00701.

Details of the analytical method, information on the textile samples, method detection limits, and concentrations of target chemicals sorted by use and fabric type (PDF)

\section{AUTHOR INFORMATION}

\section{Corresponding Author}

*Phone: +1-518-474-0015; fax: +1-518-473-2895; E-mail: kurunthachalam.kannan@health.ny.gov.

ORCID $\odot$

Kurunthachalam Kannan: 0000-0002-1926-7456

Notes

The authors declare no competing financial interest.

\section{ACKNOWLEDGMENTS}

We thank Mr. Karl Brosch for help with the collection of samples.

\section{REFERENCES}

(1) Henry, H.; Neville, K. Handbook of Epoxy Resins; McGraw-Hill: New York, 1982.

(2) Brem, S.; Grob, K.; Biedermann, M. Method for determining novolac glycidyl ether (NOGE) and its chlorohydrins in oily canned foods. Food Addit. Contam. 2001, 18 (7), 655-672.

(3) Coulier, L.; Bradley, E. L.; Bas, R. C.; Verhoeckx, K. C.; Driffield, M.; Harmer, N.; Castle, L. Analysis of reaction products of food contaminants and ingredients: bisphenol A diglycidyl ether (BADGE) in canned foods. J. Agric. Food Chem. 2010, 58 (8), 4873-4882.

(4) Chen, M. Y.; Ike, M.; Fujita, M. Acute toxicity, mutagenicity, and estrogenicity of bisphenol-A and other bisphenols. Environ. Toxicol. 2002, 17 (1), 80-86.

(5) Kitamura, S.; Suzuki, T.; Sanoh, S.; Kohta, R.; Jinno, N.; Sugihara, K.; Yoshihara, S.; Fujimoto, N.; Watanabe, H.; Ohta, S. Comparative study of the endocrine-disrupting activity of bisphenol A and 19 related compounds. Toxicol. Sci. 2005, 84 (2), 249-259.

(6) Schlumpf, M.; Cotton, B.; Conscience, M.; Haller, V.; Steinmann, B.; Lichtensteiger, W. In vitro and in vivo estrogenicity of UV screens. Environ. Health Perspect. 2001, 109 (3), 239-244. 
(7) Schreurs, R. H.; Sonneveld, E.; Jansen, J. H.; Seinen, W.; van der Burg, B. Interaction of polycyclic musks and UV filters with the estrogen receptor (ER), androgen receptor (AR), and progesterone receptor (PR) in reporter gene bioassays. Toxicol. Sci. 2005, 83 (2), 264-272.

(8) Satoh, K.; Ohyama, K.; Aoki, N.; Iida, M.; Nagai, F. Study on anti-androgenic effects of bisphenol a diglycidyl ether (BADGE), bisphenol F diglycidyl ether (BFDGE) and their derivatives using cells stably transfected with human androgen receptor, AR-EcoScreen. Food Chem. Toxicol. 2004, 42 (6), 983-993.

(9) Nakazawa, H.; Yamaguchi, A.; Inoue, K.; Yamazaki, T.; Kato, K.; Yoshimura, Y.; Makino, T. In vitro assay of hydrolysis and chlorohydroxy derivatives of bisphenol A diglycidyl ether for estrogenic activity. Food Chem. Toxicol. 2002, 40 (12), 1827-1832.

(10) Terasaki, M.; Kazama, T.; Shiraishi, F.; Makino, M. Identification and estrogenic characterization of impurities in commercial bisphenol A diglycidyl ether (BADGE). Chemosphere 2006, 65 (5), 873-880.

(11) Cabaton, N.; Dumont, C.; Severin, I.; Perdu, E.; Zalko, D.; Cherkaoui-Malki, M.; Chagnon, M. C. Genotoxic and endocrine activities of bis(hydroxyphenyl)methane (bisphenol F) and its derivatives in the HepG2 cell line. Toxicology 2009, 255 (1-2), 15-24.

(12) Suarez, S.; Sueiro, R. A.; Garrido, J. Genotoxicity of the coating lacquer on food cans, bisphenol A diglycidyl ether (BADGE), its hydrolysis products and a chlorohydrin of BADGE. Mutat. Res., Genet. Toxicol. Environ. Mutagen. 2000, 470 (2), 221-228.

(13) Hyoung, U. J.; Yang, Y. J.; Kwon, S. K.; Yoo, J. H.; Myoung, S. C.; Kim, S. C.; Hong, Y. P. Developmental toxicity by exposure to bisphenol A diglycidyl ether during gestation and lactation period in Sprague-Dawley male rats. J. Prev. Med. Public Health 2007, 40 (2), 155-161.

(14) Sueiro, R. A.; Suarez, S.; Araujo, M.; Garrido, M. J. Study on mutagenic effects of bisphenol A diglycidyl ether (BADGE) and its derivatives in the Escherichia coli tryptophan reverse mutation assay. Mutat. Res., Genet. Toxicol. Environ. Mutagen. 2006, 609 (1), 11-16.

(15) Environment and Human Health, Inc. Plastics that may be harmful to children and reproductive health. North Haven, CT, 2008.

(16) Welshons, W. V.; Nagel, S. C.; vom Saal, F. S. Large effects from small exposures, III. Endocrine mechanisms mediating effects of bisphenol A at levels of human exposure. Endocrinology 2006, 147, s56-s69.

(17) Kang, D.; Kwon, S.; Yang, Y.; Chun, Y.; Hong, Y. Decreased of clusterin mRNA expression of epididymis following exposure to bisphenol A diglycidyl ether during gestation and lactation in SpragueDawley rats. J. Environ. Toxicol. 2008, 23 (4), 291-299.

(18) Liao, C.; Kannan, K. High levels of bisphenol A in paper currencies from several countries, and implications for dermal exposure. Environ. Sci. Technol. 2011, 45 (16), 6761-6768.

(19) Xie, Y.; Bao, Y.; Wang, H.; Cheng, Y.; Qian, H.; Yao, W. Release of bisphenols from can coatings into canned beer in China market. J. Sci. Food Agric. 2015, 95 (4), 764-770.

(20) Bailey, B. A.; Hoekstra, E. J. Background Paper on Sources and Occurrence of Bisphenol A Relevant for Exposure of Consumers, World Health Organization, 2011.

(21) Goodson, A.; Robin, H.; Summerfield, W.; Cooper, I. Migration of bisphenol A from can coating-effects of damage, storage conditions and heating. Food Addit. Contam. 2004, 21, 1015-1026.

(22) Liao, C.; Kannan, K. Widespread occurrence of benzophnonetype UV light filters in personal care products from China and the United States: an assessment of human exposure. Environ. Sci. Technol. 2014, 48 (7), 4103-4109.

(23) Cabado, A. G.; Aldea, S.; Porro, C.; Ojea, G.; Lago, J.; Sobrado, C.; Vieites, J. M. Migration of BADGE (bisphenol A diglycidyl-ether) and BFDGE (bisphenol F diglycidyl-ether) in canned seafood. Food Chem. Toxicol. 2008, 46 (5), 1674-1680.

(24) Lintschinger, J.; Rauter, W. Simultaneous determination of bisphenol A-diglycidyl ether, bisphenol F-diglycidyl ether and their hydrolysis and chlorohydroxy derivatives in canned foods. Eur. Food Res. Technol. 2000, 211 (3), 211-217.
(25) Wang, L.; Liao, C.; Liu, F.; Wu, Q.; Guo, Y.; Moon, H. B.; Nakata, H.; Kannan, K. Occurrence and human exposure of phydroxybenzoic acid esters (parabens), bisphenol A diglycidyl ether (BADGE), and their hydrolysis products in indoor dust from the United States and three East Asian countries. Environ. Sci. Technol. 2012, 46 (21), 11584-11593.

(26) Xue, J.; Venkatesan, A. K.; Wu, Q.; Halden, R. U.; Kannan, K. Occurrence of Bisphenol A Diglycidyl Ethers (BADGEs) and Novolac Glycidyl Ethers (NOGEs) in Archived Biosolids from the U.S. EPA's Targeted National Sewage Sludge Survey. Environ. Sci. Technol. 2015, 49 (11), 6538-6544.

(27) Xue, J.; Wu, Q.; Sakthivel, S.; Pavithran, P. V.; Vasukutty, J. R.; Kannan, K. Urinary levels of endocrine-disrupting chemicals, including bisphenols, bisphenol A diglycidyl ethers, benzophenones, parabens, and triclosan in obese and non-obese Indian children. Environ. Res. 2015, 137, 120-128.

(28) Wang, L.; Xue, J.; Kannan, K. Widespread occurrence and accumulation of bisphenol A diglycidyl ether (BADGE), bisphenol $\mathrm{F}$ diglycidyl ether (BFDGE) and their derivatives in human blood and adipose fat. Environ. Sci. Technol. 2015, 49 (5), 3150-3157.

(29) Yu, X.; Xue, J.; Yao, H.; Wu, Q.; Venkatesan, A. K.; Halden, R. U.; Kannan, K. Occurrence and estrogenic potency of eight bisphenol analogs in sewage sludge from the US EPA targeted national sewage sludge survey. J. Hazard. Mater. 2015, 299, 733-739.

(30) Xue, J.; Wan, Y.; Kannan, K. Occurrence of bisphenols, bisphenol A diglycidyl ethers (BADGEs), and novolac glycidyl ethers (NOGEs) in indoor air from Albany, New York, USA, for inhalation exposure. Chemosphere 2016, 151, 1-8.

(31) Wan, Y.; Xue, J.; Kannan, K. Occurrence of benzophenone-3 in indoor air from Albany, New York, USA, and its implications for inhalation exposure. Sci. Total Environ. 2015, 537, 304-308.

(32) Wang, W.; Abualnaja, K. O.; Asimakopoulos, A. G.; Covaci, A.; Gevao, B.; Johnson-Restrepo, B.; Kumosani, T. A.; Malarvannan, G.; Minh, T. B.; Moon, H. B.; Nakata, H.; Sinha, R. K.; Kannan, K. A comparative assessment of human exposure to tetrabromobisphenol A and eight bisphenols including bisphenol A via indoor dust ingestion in twelve countries. Environ. Int. 2015, 83, 183-191.

(33) Lacasse, K.; Baumann, W. Textile Chemicals: Environmental Data and Facts. Springer Berlin Heidelberg: New York, 2004; page 609.

(34) O Ecotextiles. Choosing a fabric for your new sofa.https:// oecotextiles.wordpress.com/tag/bisphenol-a/ (accessed Jan 20, 2017).

(35) O Ecotextiles. Bisphenol A in textile processing? https:// oecotextiles.wordpress.com/2011/12/16/bisphenol-a-in-textileprocessing/ (accessed Jan 20, 2017).

(36) Bisphneol A. Directive 2014/81/EU amending Appendix C of Annex II to directive 2009/48/EC. http://www.btha.co.uk/wpcontent/uploads/2015/06/BPA-Guide-Version-1.pdf (accessed Jan 20, 2017).

(37) Liu, W.; Xue, J.; Kannan, K. Benzothiazoles and Benzotriazoles in Textiles and their Implications for Human Exposure. Sci. Total Environ. 2017, 592, 91-96.

(38) Bolks, A.; DeWire, A.; Harcum, J. B. Baseline assessment of leftcensored environmental data using R. Tech Notes 10, Developed for U.S. Environmental Protection Agency by Tetra Tech, Inc., Fairfax, VA, 2014, 28 pp; https://www.bae.ncsu.edu/programs/extension/ wqg//319monitoring/TechNotes/technotes10_left_censor_r.pdf (accessed Jan 11, 2017).

(39) Huston, C.; Juarez-Colunga, E. Guidelines for computing summary statistics for data-sets containing non-detects, 2009; http:// bvcentre.ca/files/research_reports/08-03GuidanceDocument.pdf (accessed Jan 9, 2017).

(40) U.S. EPA. Exposure Factors Handbook, EPA/600/R-09/052F; U.S. Environmental Protection Agency: Washington, DC, 2011.

(41) BfR. Introduction to the Problems Surrounding Garment Textiles, Updated BfR Opinion No. 041/2012, July 2012; http:/ /www. bfr.bund.de $/ \mathrm{cm} / 349 /$ introduction-to-the-problems-surroundinggarment-textiles.pdf (accessed Jan 11, 2017). 
(42) Rovira, J.; Nadal, M.; Schuhmacher, M.; Domingo, J. L. Human exposure to trace elements through the skin by direct contact with clothing: Risk assessment. Environ. Res. 2015, 140, 308-316.

(43) DermNet New Zealand. What are benzophenones and where are they found?, http://www.dermnetnz.org/topics/allergy-tobenzophenones/ (accessed on Jan 16, 2017).

(44) May, C. A. Epoxy Resins: Chemistry and Technology, 2nd ed.; CRC Press: New York, 1988.

(45) Greenpeace. Dirty laundry: Unravelling the corporate connections to toxic water pollution in China; Greenpeace International: Amsterdam, The Netherlands, 2014. 